\title{
DEMONSTRATION OF FATIGUE FOR LTO LICENSE OF NPP BORSSELE
}

\author{
M.H.C. Hannink ${ }^{1}$, F.J. Blom ${ }^{1}$, P.W.B. Quist ${ }^{2}$, A.E. de Jong ${ }^{2}$, and W. Besuijen ${ }^{2}$ \\ ${ }^{1}$ NRG, The Netherlands \\ ${ }^{2}$ EPZ, The Netherlands
}

\begin{abstract}
Long Term Operation (LTO) of nuclear power plants (NPPs) requires an ageing management review and a revalidation of Time Limited Ageing Analyses (TLAAs) of structures and components important for nuclear safety. An important ageing effect to manage is fatigue. Generally, the basis for this is formed by the fatigue analyses of the safety relevant components. In this paper, the methodology for the revalidation of fatigue TLAAs is demonstrated for LTO of NPP Borssele in the Netherlands.

The LTO demonstration starts with a scoping survey to determine the components and locations having relevant fatigue loadings. The scope was defined by assessment against international practice and guidelines and engineering judgment. Next, a methodical review was performed of all existing fatigue TLAAs. This also includes the latest international developments regarding environmental effects. In order to reduce conservatism, a comparison was made between the number of cycles in the analyses and the number of cycles projected to the end of the intended LTO period. The projected number of cycles is based on transient counting. The loading conditions used in the analyses were assessed by means of temperature measurements by the fatigue monitoring system (FAMOS). As a result of the review, further fatigue assessment or assessment of environmental effects was necessary for certain locations. New analyses were performed using state-of-the-art calculation and assessment methods. Fatigue management of the NPP is ensured by means of the fatigue concept where load monitoring, transient counting and fatigue assessment are coupled through an integrated approach during the entire period of LTO.
\end{abstract}

\section{INTRODUCTION}

NPP Borssele is one of the first NPPs in Europe whose originally planned operation time of 40 years has been extended to 60 years. In the original Safety Report of the plant, which is in commercial operation since 1973, ageing stressors for 40 years of operation were assumed. Over the last few years, NPP Borssele has carried out an LTO demonstration programme to demonstrate safe operation until 2034. The programme was set up according to IAEA guidelines of Safety Report No. 57 (2008) and Safety Guide No. NS-G-2.12 (2009). A schematic overview of the adopted approach is depicted in Figure 1.

One of the steps in the demonstration of safe LTO is the revalidation of fatigue TLAAs (marked red in Figure 1). It has to be demonstrated that the fatigue TLAAs have enough safety margin until the end of the intended period of LTO and that fatigue ageing effects are adequately managed. In this paper, the methodology is presented that was jointly developed for this by NRG and utility EPZ. Based on the LTO assessment, the license of NPP Borssele was revised comprising operation until 2034 (60 years of operation).

A schematic overview of the LTO fatigue programme of NPP Borssele is shown in Figure 2. In the schedule the following items can be identified: 
Division III

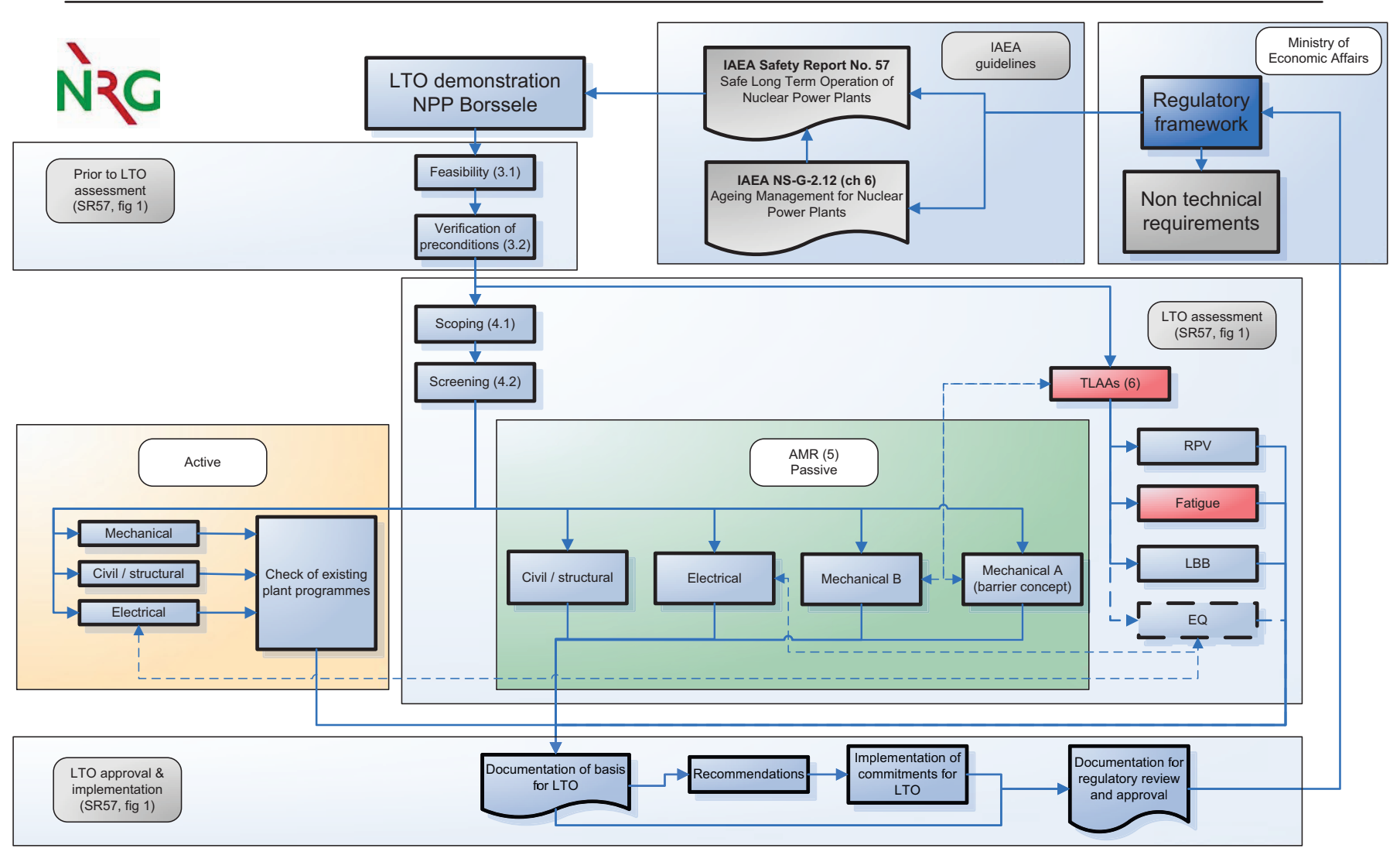

Figure 1. Schematic overview of LTO fatigue programme within LTO demonstration programme.

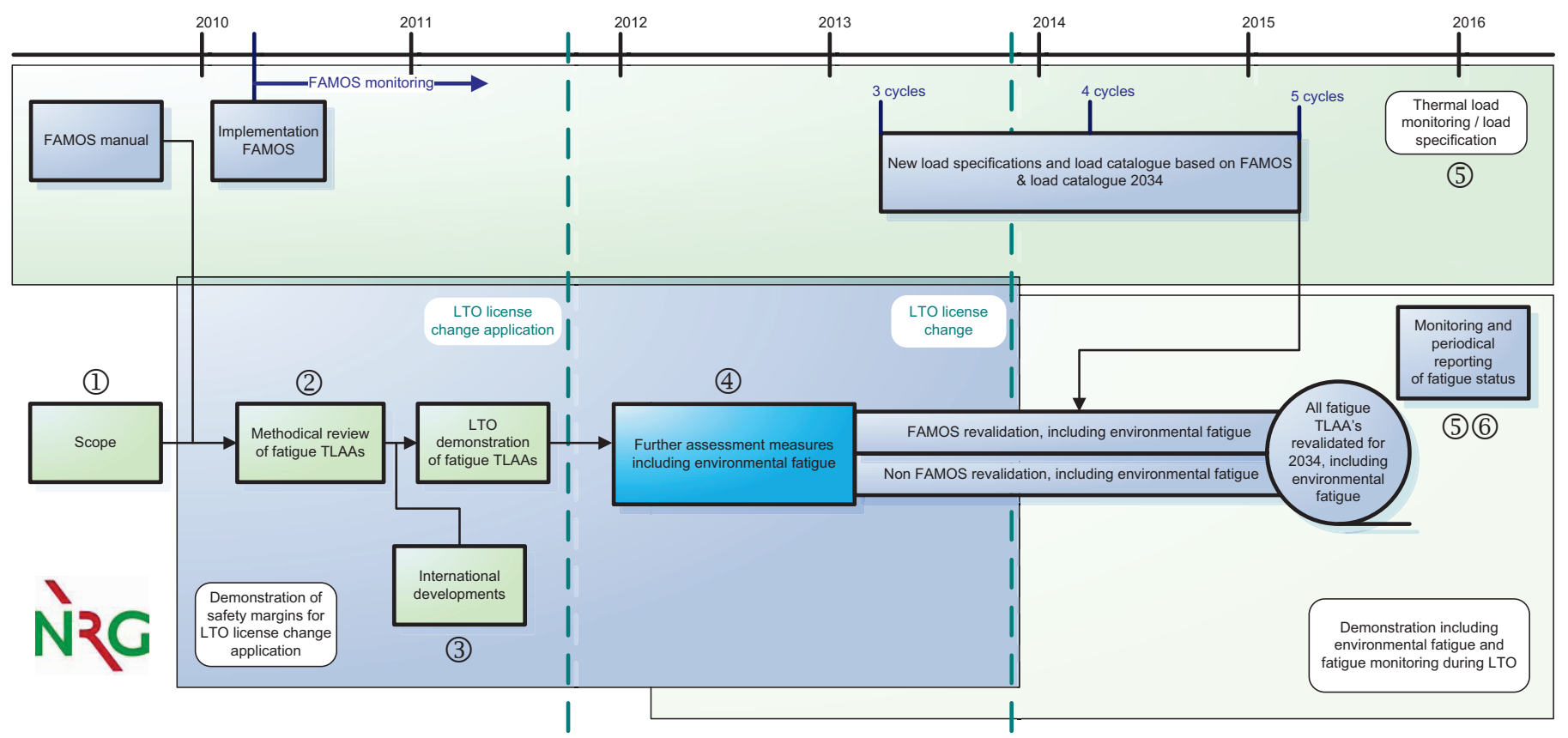

Figure 2. Schematic overview of LTO fatigue programme of NPP Borssele. 

1. Scope
2. Methodical review of fatigue TLAAs
3. International developments
4. Further assessment measures
5. Load monitoring
6. Fatigue management

In this paper, these items will be addressed in the same order. A picture of NPP Borssele is shown in Figure 3.

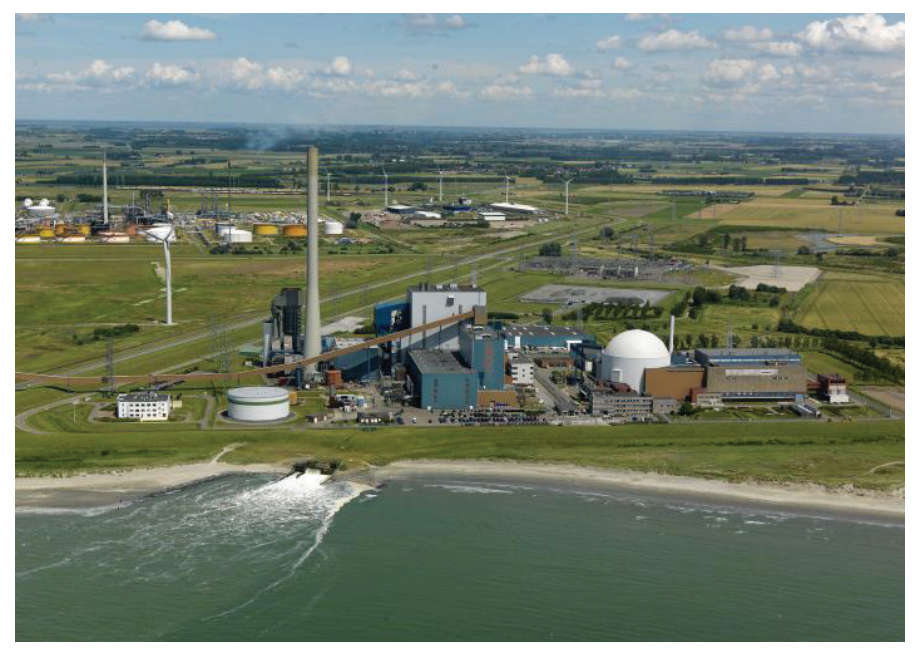

Figure 3. NPP Borssele, The Netherlands.

\section{SCOPE}

The first step in the revalidation of fatigue TLAAs is to determine the components and locations for which fatigue assessments are relevant. For completeness, this was done independently of the available existing fatigue analyses which are part of the current design base. A first definition of the scope was made by assessment against international practice and guidelines and engineering judgment. Then, the scope was verified by comparing it to the scope of a similar NPP in Germany and the set of fatigue analyses available at NPP Borssele. The four steps that were taken are summarized as follows:

1. Identify components

2. Identify component locations

3. Additional existing fatigue analysis locations

4. Comparison to scope of similar NPP

In the first step, the scope of fatigue relevant components was defined. This was done based on the safety functions of Systems, Structures and Components (SSCs) as defined in IAEA Safety Reports Series No. 57 (2008). As a result, the following set of components was selected:

- Reactor pressure vessel

- Steam generator

- Pressurizer

- Main coolant pumps

- Main coolant piping 
- Surge line

- Spray lines and auxiliary spray lines

- Feedwater piping

- Main steam piping

Then, the locations of the selected components were determined that require a fatigue assessment. This selection was made based on assessment against international practice and guidelines and engineering judgment. Examples of international guidelines that were used are IAEA-TECDOCs on ageing of different components, NUREG 1801 (2005), NUREG/CR-6260 (1995), ASME Boiler and Pressure Vessel Code, and KTA standards. Also, design and manufacturing specifications of the components and the results of the 10-yearly periodic safety review were included in the survey.

In the third step, locations with existing fatigue TLAAs were added to the scope, in line with US nuclear guidance on license renewal NEI 95-10 (2005). Finally, the scope consisted of 50 component locations that had to be assessed for fatigue.

As a last step, a verification was made by comparing the scope of NPP Borssele with the scope of a similar NPP in Germany. Herewith it was demonstrated that the scope of NPP Borssele is in line with international practice.

\section{METHODICAL REVIEW}

For all component locations in the scope, a methodical review of the fatigue analyses was performed. With these reviews, the safety margins for LTO were identified. The reviews were performed in a systematic way by applying a list of evaluation criteria on a wide range of topics to each analysis. The topics include: geometry, material properties, boundary conditions, analysis method, loads, fatigue analysis method, conservatism/margins, relevant operating experience, fatigue monitoring, and environment.

To assess the fatigue status of the different locations for LTO, the loads applied in the fatigue analyses were revalidated until 2034. First, a thorough survey was made of the applied load cases. Next, the numbers of cycles associated with these load cases were projected until 2034.

In most cases, the projected numbers of cycles until 2034 are based on numbers of cycles that actually occurred in the plant so far. Figure 4 shows an example of such an extrapolation. The slope of the projected line was determined by averaging the counted number of cycles, without the higher frequency of occurrences during the start-up phase of the reactor (i.e. the first two years). In the case no counts were available, e.g. for emergency cases, a projected number of cycles of at least 1 was taken into account.

Most of the components of NPP Borssele are in operation since the commissioning of the plant. During a modification project that has taken place at the plant in 1997, various components have been (re)placed or changed. This means that fatigue analyses were performed for different operation times and that also the numbers of load cycles experienced by the components differ. 


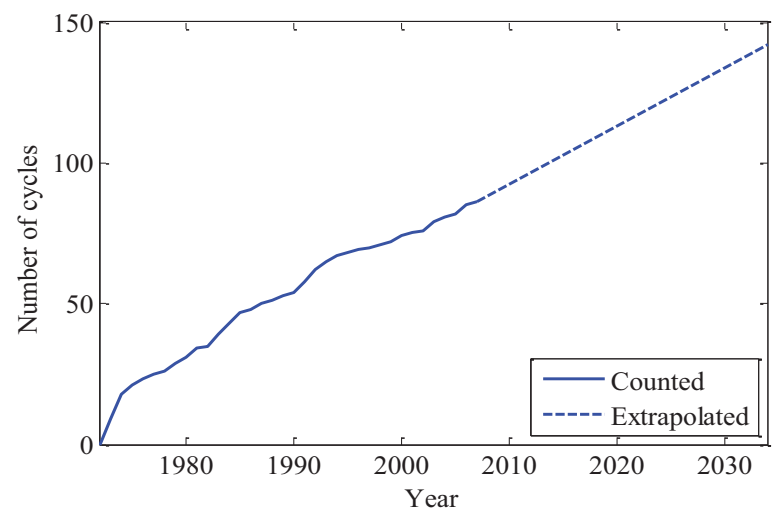

Figure 4. Extrapolation to determine projected number of cycles.

Depending on the specifications of the components, the fatigue assessments were performed using different codes. Over the years, different versions of the German safety standards KTA and the ASME Boiler and Pressure Vessel Code were used. For the revalidation of the fatigue analyses, a comparison was made between the most recent versions of these codes and the versions used in the analyses. Since no major differences were found in the assessment methods for fatigue, guidelines used in the original analyses were found to be adequate for LTO.

As a result of the methodical review, all existing fatigue analyses were assessed and, if possible, usage factors were revalidated until 2034. For 44 of the 50 component locations it was demonstrated that the cumulative usage factors until 2034 are within the regulatory limits. For 6 component locations further fatigue assessment was necessary. In the section "Further Assessment Measures", the approach followed for the new analyses of these components is presented.

\section{INTERNATIONAL DEVELOPMENTS}

In addition to the items addressed in the methodical review, there is a number of topics that is still under international discussion. The two most important are high-cycle thermal fatigue and environmentally assisted fatigue. Both are discussed in this section.

\section{High-Cycle Thermal Fatigue}

Worldwide, cracking events due to (high-cycle) thermal fatigue phenomena, which were not included in the initial design, have occurred at several NPPs. At NPP Borssele, structural integrity regarding most of the thermal fatigue phenomena (low-cycle fatigue) is covered by the design analyses and the fatigue monitoring system FAMOS. High-cycle temperature fluctuations (for example in a mixing tee, see Figure 5), however, are too fast to be detected by common plant instrumentation systems and are generally not included in the design analyses.

To assess the possibility of high-cycle fatigue damage at NPP Borssele, an overview was created of international high-cycle thermal fatigue events. In literature various overviews of such events are given (IAEA-TECDOC-1361, 2003; Gosselin et al., 2007; Hirschberg, 2000; Paffumi and Radu, 2009). At NPP Borssele, feedback on external events related to ageing issues is recorded in an ageing management database. Most literature cases were therefore already documented. Events requiring a more extensive analysis are subsequently discussed in separate reports, where the influence on NPP Borssele components is assessed. Based on the available information, none of the reported events appeared to be applicable to 
NPP Borssele. International developments in this field will be followed until the end of the intended period of LTO.

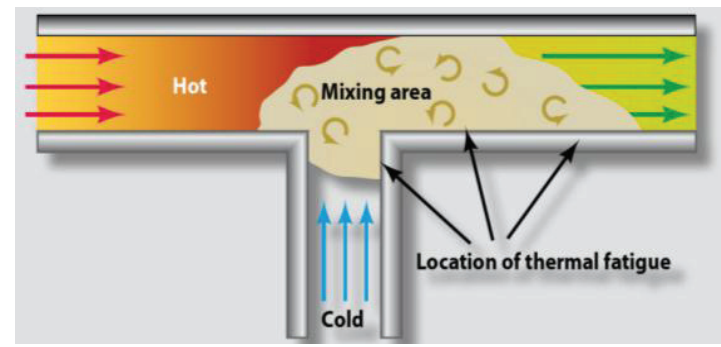

Figure 5. Example of high-cycle thermal fatigue event.

\section{Environmental Fatigue}

Another topic that is addressed world-wide is the effect of the reactor coolant environment on fatigue life. To define an adequate procedure for incorporating environmental effects in the fatigue assessment for LTO, first a survey was conducted on the latest international developments in this field. At the time of the survey, most developments were taking place in the US and Germany. Since NPP Borssele was designed by Siemens/KWU (Germany), it was decided to follow the environmental fatigue guidelines of the German safety standards KTA 3201.2 (2011). The first step in these guidelines is to perform a screening with awareness thresholds of 0.2 for austenitic materials and 0.4 for ferritic materials. If the cumulative usage factor is smaller than these thresholds, no additional measures have to be taken regarding environmental effects. If the cumulative usage factor exceeds the awareness thresholds, one of the following measures has to be taken (KTA 3201.2, 2011):

- Including the component into a fatigue monitoring programme according to KTA 3201.4 (1999)

- Performing appropriate experiments

- Detailed fatigue analyses taking into account environmental fatigue correction factors

At NPP Borssele, the last option was applied. A new detailed fatigue analysis was performed including environmental fatigue correction factors (Fen factors). The Fen factors were calculated according to NUREG-CR/5704 (1999) for austenitic steels and NUREG-CR/6583 (1998) for ferritic steels. To calculate the Fen factors under conditions where temperature and strain rate are changing over time, the so-called modified rate approach (Chopra and Shack, 2006) was used.

By screening the component locations, it was shown that for a few of these locations environmental fatigue correction factors had to be applied.

\section{FURTHER ASSESSMENT MEASURES}

As discussed in the previous sections, for certain component locations further fatigue assessment was required to demonstrate safe operation for the period of LTO. For these locations, new fatigue analyses were performed including the assessment of environmental fatigue.

The first step in the further assessment measures was a reassessment of the load specifications. In the load specifications, the temperature transients are defined that have to be taken into account in the fatigue analyses. In some cases, the design transients as used in the original fatigue analyses are very conservative with respect to the actual transients. To reduce this conservatism, a set of new temperature 
transients was defined based on FAMOS measurements. Before incorporating them into the updated load specifications, the effects of the measured transients were assessed by the NRG fatigue model.

After updating the load specifications, new fatigue analyses were performed using state-of-the-art calculation techniques and assessment methods. Depending on the level of detail needed, different fatigue assessment methods were applied. Figure 6 summarizes these methods in order of increasing complexity. The level of detail needed depends on the necessity to reduce conservatism in the assessment. The more conservatism is allowed, the less time consuming the calculations. All fatigue analyses were performed according to ASME Boiler and Pressure Vessel Code, Section III, Division 1 or equivalent methods described in the KTA safety standards. In method 1 and 2, plastic effects are taken into account by multiplying the alternating stress intensities resulting from an elastic analysis by so-called $\mathrm{Ke}$ or $\mathrm{Kv}$ factors. In method 3, usage factors are determined by performing elastic-plastic analyses. Fatigue assessment method 1 is available in the finite element (FE) software ANSYS that was used. For the other two assessment methods, NRG developed a fatigue analysis module that can be used in combination with any FE program. If the resulting cumulative usage factors were larger than the awareness thresholds for environmentally assisted fatigue, environmental fatigue correction factors were applied as presented in the previous section. Also for this, the NRG fatigue analysis module was used.

\begin{tabular}{|c|c|c|}
\hline $\begin{array}{l}\text { 1. Standard method } \\
\text { Simplified elastic-plastic fatigue analysis }\end{array}$ & & Conservatism \\
\hline $\begin{array}{l}\text { 2. Advanced simplified method } \\
\text { Simplified elastic-plastic fatigue analysis } \\
\text { with ASME code case }\end{array}$ & & \\
\hline $\begin{array}{l}\text { 3. Advanced method } \\
\text { Elastic-plastic fatigue analysis }\end{array}$ & Detail & \\
\hline
\end{tabular}

Figure 6. Fatigue assessment methods.

With the results of the new fatigue analyses, it has been demonstrated that for the pressure boundaries of all locations, the cumulative usage factors until the end of the intended LTO period are within the regulatory limits. The results of the measures taken for the locations that needed further assessment were presented before entering LTO.

\section{LOAD MONITORING}

Temperature fluctuations at the fatigue sensitive locations of NPP Borssele are monitored by the Fatigue Monitoring System FAMOS (installed by Areva). The monitoring system was implemented during the annual refuelling outage in April 2010. A total of 25 measurement sections were installed at different locations. At locations where stratification was expected (14 out of 25), the measurements sections contain 7 thermocouples. An example of this are the 3 measurement sections on the surge line, as shown in Figure 7. At the other locations, 2 thermocouples are present.

The temperature measurements registered by FAMOS are used for two different purposes (see also Figure 2). First of all, they were used for verification and update of the load specifications and load catalogue. The updated versions of these documents form the basis of the fatigue analyses until 2034. Five cycles of measurements were used for verification of the load specifications and load catalogue to have a statistical representation of the thermal transients associated with the different load cases. 
Secondly, FAMOS will be used for fatigue monitoring. During the entire period of LTO, temperature measurements will be made to register thermal transients at the different locations. Based on these transients and the underlying fatigue analyses, the fatigue status will be reported annually.

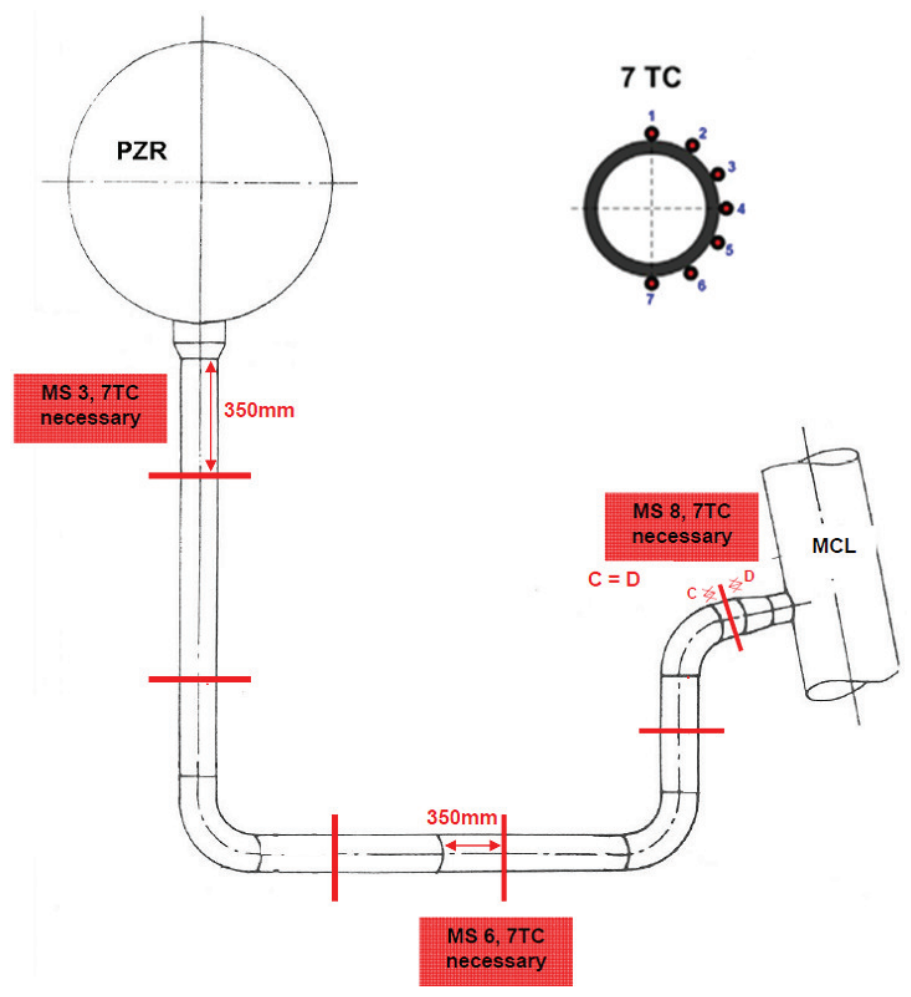

Figure 7. FAMOS measurement sections on surge line.

\section{FATIGUE MANAGEMENT}

The basis of the fatigue analyses until 2034 is formed by the load catalogue and the load specifications of the different components. In the load catalogue a description is given of the possible load cases and the projected numbers of cycles until the intended end of the LTO period. The load specifications define for each component the temperature and pressure transients that are associated with the different load cases.

To ensure that the assumptions that were made in the fatigue analyses remain valid during the entire period of LTO, a yearly overview will be made of the fatigue status. This is done through an integrated approach that couples load monitoring, transient counting and fatigue assessment.

\section{CONCLUSION}

In this paper, the methodology is presented for the revalidation of fatigue TLAAs for LTO of NPP Borssele in the Netherlands. The different steps of the developed programme are in line with the international standards and guidelines. Based on the LTO assessment, the license of NPP Borssele was revised comprising operation until 2034 (60 years of operation). Fatigue management of NPP Borssele is ensured by means of the fatigue concept where load monitoring, transient counting and fatigue assessment are coupled through an integrated approach during the entire period of LTO. A sound basis was developed for the prevention of crack initiation by fatigue. 


\section{ABBREVIATIONS}

FAMOS Fatigue Monitoring System

FE Finite element

LTO Long Term Operation

NPP Nuclear power plant

PPS Plant monitoring system

SSCs Systems, Structures and Components

TLAAs Time Limited Ageing Analyses

\section{REFERENCES}

Ageing Management for Nuclear Power Plants (2009). Safety Guide No. NS-G-2.12, International Atomic Energy Agency, Vienna.

Assessment and management of ageing of major nuclear power plant components important to safety: Primary piping in PWRs (2003). IAEA-TECDOC-1361, International Atomic Energy Agency.

Paffumi, E. and Radu, V. (2009). Status on the knowledge on crack network evolution under spectrum loading; Crack propagation and possible arrest/penetration, Report NULIFE (09) 10.

Chopra, O.K. and Shack, W.J. (1998). Effects of LWR Coolant Environments on Fatigue Design Curves of Carbon and Low-Alloy Steels, Technical Report NUREG/CR-6583, ANL-97/18, U.S. Nuclear Regulatory Commission.

Chopra, O.K. (1999). Effects of LWR Coolant Environments on Fatigue Design Curves of Austenitic Stainless Steels, Technical Report NUREG/CR-5704, ANL-98/31, U.S. Nuclear Regulatory Commission.

Chopra, O.K. and Shack, W.J. (2006). Effect of LWR Coolant Environments on the Fatigue Life of Reactor Materials, NUREG/CR-6909.

Gosselin, S.R., Simonen, F.A., Heasler, P.G. and Doctor, S.R. (2007). Fatigue Crack Flaw Tolerance in Nuclear Power Plant Piping; A basis for Improvements to ASME Code Section XI Appendix L, NUREG/CR-6934, PNNL-16192.

Hirschberg, P. (2000). Operating experience regarding thermal fatigue of unisolable piping connected to PWR reactor coolant systems (MRP-25), Report 1001006, EPRI, Palo Alto (CA), US.

Industry Guidelines For Implementing The Requirements of 10 CFR Part 54 - The License Renewal Rule (2005). NEI 95-10 Revision 6, Nuclear Energy Institute.

KTA 3201.2 (2011). Komponenten des Primärkreises von Leichtwasserreaktoren, Teil 2: Auslegung, Konstruktion und Berechnung, Änderungsentwurf, Safety Standards of the Nuclear Safety Standards Commission (KTA).

KTA 3201.4 (1999). Components of the Reactor Coolant Pressure Boundary of Light Water Reactors, Part 4: In-service Inspections and Operational Monitoring, Safety Standards of the Nuclear Safety Standards Commission (KTA).

NUREG 1801 (2005). Generic Ageing Lessons Learned (GALL) Report, Vol.1, Rev.1 and Vol.2, Rev.1.

Safe Long Term Operation of Nuclear Power Plants (2008). Safety Report Series No. 57, International Atomic Energy Agency, Vienna.

Ware, A.G., Morton, D.K. and Nitzel, M.E. (1995). Application of NUREG/CR-5999 Interim Fatigue Curves to Selected Nuclear Power Plant Components, NUREG/CR-6260. 